\title{
Communication and Operation of TV WeChat Official Account
}

\author{
OU Yi-fan \\ Jiangsu Second Normal University, Jiangsu Province, China
}

\begin{abstract}
WeChat is a pretty hot social software in China, which is also a free mobile application with the core function of multimedia information communication launched by Tencent in 2011 and has been widely popularized and used in China. As an auxiliary function module, the official accounts also provide a channel to deeply communicate with specific groups. At present, there are totally 30,000 certified WeChat official accounts, and more than 70\% of which are enterprise accounts. WeChat official accounts supply a good chance to government departments, enterprises, media and personal to propagandize and popularize their information. Therefore, various media choose WeChat public platform as trial for new modes of news communication.
\end{abstract}

Keywords: WeChat public platform, management, communication

\section{Development Overview of TV WeChat Public Platforms}

Public platform for media is the most active and most influential one among the current WeChat official accounts. The major operation subjects of such platform mainly contain: Firstly, portal channels, such as Tencent Technologies and Sina Technologies; Secondly, traditional media, including radio and television, newspapers and magazines such as People's Daily, CCTV News, and Southern Weekly etc.; Thirdly, we media. At present, a large number of public intellectuals, or well-known media professionals have emerged in China, who are supported and affirmed by lots of fans, such as the official account "Logical Thinking", operated by the famous media professional Luo Zhen-yu; Fourthly, independent tech media, such as famous tech media companies, 36Kr and Huxiu.com, etc. (ZHAO \& LI, 2013).

As we all know, TV channels have strong influence and user base, so that the propagation effect can be further expanded if it can be propagated via WeChat.

\section{Transmission Characteristics of TV WeChat Public Platform}

\section{Accurate Positioning and Well-targeted Content of WeChat Official Accounts}

In April, 2015, the results of the 12th National Reading Survey shows that WeChat reading was firstly included in the survey, and the ratio of reading articles published on WeChat reaches up to $20.9 \%{ }^{1}$, which indicates that WeChat has become a major way for the public to obtain news information.

Information push is the major transmission method of WeChat official accounts. Compared with the fleeting programs on TV channel, information push can enable users look up information at all times and places, browse historical information, and receive latest information (HUANG \& PENG, 2016).

\footnotetext{
OU Yi-fan, Lecturer, School of Modern Media, Jiangsu Second Normal University.

1 Twelfth National Reading survey: The average per person per day to read WeChat over 40 minutes. http://news.xinhuanet.com/newmedia/2015-04/21/c_134168413.htm
} 
Now the writer classifies the information into the following types: news information, wonderful tidbits and trailers of programs, sharing of knowledge and experience. According to data provided by Index of New Media from October 14 to October 17, 2015, we can find that all channels of CCTV push relevant news information based on the positioning of each channel. For example, the WeChat official account of CCTV News mainly pushes news information, the account of CCTV Sports mainly pushes sports news, the account of CCTV International mainly pushes various international politics hot, the account of CCTV Variety mainly pushes information of various comprehensive entertainment programs, and the account of CCTV Music mainly pushes all kinds of classic music ${ }^{2}$. Different WeChat official accounts have reflected the different development focuses of specialized TV media with clear positioning and accurate direction (LIU, YANG, \& SHEN, 2014).

Comparing with WeChat official accounts of all CCTV channels, the accounts of local TV stations mainly push wonderful tidbits and trailers of various programs, in order to attract audiences, and make preparations for the promotion of audience rating for the programs. For example, Zhejiang TV is a local TV channel with a leading audience rating, which is also known for its various variety shows. Meanwhile, China Blue, the WeChat official account of Zhejiang TV, is also followed by plenty of users. We have drawn samples from October 14 to October 20,2016, and the headline news pushed within this week are: "Honest \& Adventure, we cannot help to show this innovative program to you tonight", "Battle of Voice, wanna taste the first crab? Then how?", "The singer Hebe led the fans high on her first show, but she said she was nervous", "We have a very special TV play to broadcast", and "A Mei shivered on the stage unexpectedly, how amazing the Battle of Voice is!", "I Am the Red Army is pushed on Zhejiang TV, but it is different this time". Zhejiang TV pushes the wonderful tidbits and trailers of various programs and TV plays to attract audiences, and thus to improve the audience rating of the programs ${ }^{3}$.

Table 1

Various Information Pushing Amount Within Oct. 4th-17th, 2015

\begin{tabular}{lcccl}
\hline Official accounts & Program trailers and tidbits & News information & $\begin{array}{c}\text { Sharing of knowledge } \\
\text { and experience }\end{array}$ & Activity trends \\
\hline CCTV News & 2 & 117 & 16 & 0 \\
Hunan TV & 45 & 0 & 0 & 1 \\
CCTV-4 & 4 & 17 & 42 & 0 \\
CCTV-5 & 0 & 8 & 0 & 0 \\
CCTV-1 & 33 & 6 & 10 & 1 \\
CCTV Variety & 17 & 4 & 3 & 0 \\
China Blue, Zhejiang TV & 41 & 2 & 24 & 0 \\
Jiangsu TV & 112 & 0 & 1 & 0 \\
CCTV TV play & 19 & 0 & 0 & 3 \\
CCTV Movie & 1 & 0 & 0 & 0 \\
Total & 274 & 154 & 96 & 5 \\
\hline
\end{tabular}

\section{Multi-function Custom Menus to Improve the User Experience}

To ensure users inquire the interested information more rapidly and conveniently, these WeChat official accounts have set multi-function custom menus to improve the user experience. After entering the WeChat official account, there are many primary menus, and users can choose the interested classification to enter the

\footnotetext{
${ }^{2}$ Data released by New Media Index from October 4th to October 17th, 2015.

3 Data cited from New Media Index released from October 4th to October 17th, 2015, http://www.gsdata.cn.
} 
secondary menu for information searching. For example, the WeChat official account of Hunan TV is set with three primary menus, which respectively are Youth Show, Super Menu and More Contents. After entering the Youth Show, there are secondary menus including Happy Camp, TianTian Xiang Shang, Diamond, Where Are We Going, Dad? and Up Idol. Super Menu is set with secondary menus such as wonderful recommendation, program list, $\mathrm{V}$ game, etc. Meanwhile, under More Contents are the secondary menus including Know Me, Help and Happy Community. The users can find their interested contents and information within the shortest time. Taking China Blue as another example, the WeChat official account of Zhejiang TV is set with three primary menus, Running Man, Three Dads and All Media. After clicking the Running Man, there are Voice of China 4, Running Man 3, 12 Tastes, Challenger Alliance and China Blue Live. After clicking the All Media, we can see secondary menus, Lanmei Video, Official Weibo, Official Tieba, Blue Friend Client and Official Headline.

Besides, TV official accounts also set some service called "Micro Community" to enhance the users' enthusiasm and interactivity. For example, the WeChat official account of CCTV 1 is set with the "Audience Community", the account of Hunan TV is set with "Happy Community", and the account of Zhejiang TV is set with "Blue Community". In this way, users following the official accounts can communicate with others, and provide more feedback opinions for the official accounts.

In a word, TV official accounts pay more attention to the user experience, and the all-round service to show respect to users.

\section{Reasonable Push Frequency to Enhance the User Loyalty}

To attract more users, and improve the transmission influence, WeChat official accounts must push the information punctually and reasonably, which is helpful for users to form the chronic reading, and enhance the user loyalty.

If the information is pushed too continually, it is inevitable that the information may be repeated and complex, and the users may be too bored to bear the disturbing. If the information is pushed with a low frequency, the users may feel that the official account is so worthless that they will not follow it again, and finally the official account may be obsoleted. Therefore, the reasonable and stable push frequency is helpful for the good link between the official accounts and users.

The writer has summarized the information push and reading conditions of the official accounts of various TV stations from October 4th to October 17th, 2015, in accordance with the data provided by the Index of New Media ${ }^{4}$.

For example, the official account of CCTV News mainly pushes information three times a day, which are respectively distributed in morning, noon, and evening to ensure strong timeliness of information and reasonable acceptance scope of the users. In fact, besides the TV official accounts, other paper media's WeChat official accounts are also operated with good efficiency in this aspect. For example, the WeChat official account of People's Daily pushes information about five times a day, which are also distributed in morning, noon, and evening to ensure timely communication of news information and reasonable pushing frequency. As we all know, People's Daily pushes the "News Morning Express" in the morning with contents of latest information to open a new day for users with such fresh and timely information. Meanwhile, it also pushes the "Night Reading" with motivational and inspirational stories. As many people are going to take a rest at this

${ }^{4}$ Data released by New Media Index from October 4th to October 17th, 2015. 
moment, so some news information may be not helpful for users to relax, instead, some motivational and inspirational stories may enlighten and inspire the users for a good rest. So the reasonable and suitable information push can promote user loyalty, and assist the TV official accounts in better development.

Table 2

Message Push and Reading in October 4th-17th, 2015

\begin{tabular}{llllll}
\hline Official accounts & $\begin{array}{l}\text { Total push } \\
\text { number/the number Average push } \\
\text { of messages } \\
\text { (time/item) }\end{array}$ & $\begin{array}{l}\text { Total Reading } \\
\text { interval (day) } \\
\text { amount } \\
\text { (thousand times) }\end{array}$ & $\begin{array}{l}\text { Average reading } \\
\text { amount (Time) }\end{array}$ & WCI $^{*}$ \\
\hline CCTV News & $40 / 136$ & 0.35 & 12,494 & 80,237 & 1,623 \\
Hunan TV & $17 / 46$ & 0.82 & 1,426 & 32,488 & 1,246 \\
CCTV-4 & $14 / 66$ & 1 & 865.2 & 13,019 & 1,134 \\
CCTV-5 & $2 / 8$ & 7 & 290 & 36,296 & 1,108 \\
CCTV-1 & $14 / 49$ & 1 & 344 & 6,974 & 957 \\
CCTV Variety & $10 / 24$ & 0.71 & 204 & 7,932 & 890 \\
China Blue, Zhejiang TV & $18 / 70$ & 0.77 & 296 & 4,269 & 852 \\
Jiangsu TV & $41 / 113$ & 0.34 & 253 & 2,313 & 826 \\
CCTV TV play & $6 / 25$ & 2.33 & 34 & 1,392 & 603 \\
\hline
\end{tabular}

Note. "Wechat Communication Index (WCI) means the reflection of overall popularity of WeChat and the development trend of public accounts through the communication and coverage of articles pushed by WeChat public accounts and the maturity and influence of public accounts.

\section{Diversified and Lively Contents}

To better attract the users and meet users' demand to obtain enough information, the WeChat official accounts generally push the information with the combination of pictures and characters. Taking official account of CCTV News for example, the headline news is usually presented with the combination of big picture and brief headline. And other articles may be pushed combining with thumbnail and headlines below the headline news. Such information transmitting manner is lively and vivid, and the users can understand these rapidly.

Except the simple combination of pictures and characters, now more and more TV official accounts also make full use of audio and video contents. With the application of aural and visual contents, the users may be more interested in understanding the news and the contents. For example, on official account of Jiangxu TV, video highlights of relevant programs will be broadcasted when the trailers and tidbits are pushed, and the users can click the play button to enjoy the video. Meanwhile, music related to the content of the pushed article will also be played. With the application of audio and video contents, information can be transmitted cross screens, in order to meet the users' aural and visual demands on mobile media.

\section{Two-way Communication Platforms}

With the full use of the functions and characteristics of social media and the advantages of new media platform, TV official account is a constant improvements of traditional media into media convergence, which also reflects that TV media pays more attention to the voice of audiences, and the communication with audiences.

The transmission of traditional TV media is one to many, while WeChat is one to one. With the appearing of WeChat official accounts, the traditional media has switched to transverse service platform to make up the shortcoming of TV media, that is lack of interaction. 
During the using process of WeChat official accounts, the users can leave a message in forms of voice, picture or character via the dialog box in real time, and the background editors can receive real-time information and communicate with the audiences. Meanwhile, the users can exchange and communicate with other users via the community module on the WeChat. During the Two Sessions, "CCTV News" cooperated with 24 Hours at night, pushed "Micro Two Sessions", which collected WeChat comments on a hot topic of two sessions every day, with daily reply volume of 20,000-30,000 (CAI \& WENG, 2013). Different from the "message board" of Weibo, the interaction on WeChat is more private, which is similar to the "notes", and the results counted by the editors' show that the replying quality of WeChat users is higher than the comment of Weibo users.

In a word, different from the single-direction communication mode, the TV official accounts have achieved the independent choice and two-way communication, thus the users can better voice their own opinions and suggestions, and realize their own psychological demands.

\section{Development Issues of TV WeChat Official Accounts}

\section{Insufficient Promotion}

Compared with some commercial official accounts, TV official accounts are deficient in some certain attractive manners when popularizing the accounts, for example, "China Blue, Zhejiang TV" mainly popularizes its account by pushing program tidbits, blue community, user interaction and USATON lottery-attached activities. However, users of such TV official accounts are usually the audiences interested in the TV channels, and it is hard to develop users beyond these audiences. Once the audiences change their interested points, the subscription amounts may grow negatively (HUANG \& WANG, 2015).

\section{Single and Inefficient Interaction Forms}

At present, the TV official accounts are deficient in communication with users, so the user-based consciousness shall be further strengthened.

On one side, at present, the interaction mode between TV official accounts and users is simple, which is mainly the interaction and communication based on voice and character, and the communication is short of individuation (YU, 2015). On the other side, during the communication and interaction, there are also some problems such as untimely reply. As the background may receive plenty of users' messages, the editors may put off the reply, or even not do it, which greatly cuts down the propagation and communication effect.

\section{Official Presentation and Lacking of Intimacy}

Various TV official accounts, especially CCTV, such as "CCTV News" and "CCTV-1", usually use the rigorous expressions and plenty of official phraseologies on the official accounts.

The communication of WeChat official accounts shall adapt the communication ideas and characteristics of new media, and appropriately use some Internet phraseology in order to be more approachable and enhance user loyalty (LUO, 2015).

\section{Lack of Complete Data Analysis}

The existing TV official accounts are short of complete data analysis, for example, the big background can only show some simple information, such as the increase and decrease of users and general information of subscription users. And it is impossible to know who commends or reposts the message, as well as the peak time and ebb time of reading. The TV official accounts should be further developed and designed in aspect of background operation, in order to understand the users, and provide the superior services. 


\section{Developing Suggestions on TV Official Accounts}

\section{More Interesting and Lively Headlines}

Compared with the traditional media, the communication modes of Internet platform are more lively and free, so it may be a good idea to add a vivid and lively headline while pushing the information, in order to attract the netizen.

At present, some official accounts such as CCTV News still choose the official and serious headline while pushing articles. Being different from such official accounts, some paper media official accounts prefer to use the interesting headlines, for example, LiaoShen Evening News has pushed an article read by more than 100,000 users, which reported the news that some pet dog were stolen and sold in Xita Dog Meat Street, Heping District in Shenyang City. This article was titled as I am in Xita, I wanna go home, don't eat me as I am sick, which was published from the view of animals, in order to motivate the curiosity of audiences to read more about the news.

At present, various WeChat official accounts are emerging, so TV official accounts must spend more efforts on the headlines to attract more audiences (JING, 2015).

\section{Lead Public Opinion in Interaction and Expand Two Public Opinion Fields}

The communication mode of traditional media is one-way. As the publisher of information, traditional media has occupied the advantageous position during the issuing and leading of public opinions, while the public are difficult to voice their own opinions.

Different from the traditional media, the users can voice their own opinions and suggestion via WeChat, and form the folk Internet public opinion platform (LI \& LIU, 2016) under the broad environment of Internet communication.

Meanwhile, the new media platform and traditional media platform shall form the composition forces, as well as the good interaction mechanism, in order to occupy the commanding height of public opinion, and lead the Internet public opinion to sound development. Therefore, WeChat official accounts are required to coordinate with traditional media platform, actively concern the news and current affairs, respond to and analyze the news events at first time, and gradually form the mainstream public opinion, in order to lead the public to know the truth, stabilize the emotion of the public, and make sure the public opinion system can develop in order. For example, "CCTV News" has specially reported the news that a female college student ended her own life after suffering from a telecommunication fraud, meanwhile, CCTV invited the professors from CUPL and other procuratorate office workers to carry out deep analysis on this event, such as the crime motive, crime method and the deserved punishment of the criminal and they also provided some tips and guidance to prevent fraud for the public. The analysis and guidance of the experts provides good information guidance for the public to prevent similar events from occurring again.

\section{Integrate Media Resources and Create Brand Resources}

The information communicated via WeChat is diversified, and the communication efficiency is greatly discounted due to the existing of plenty of fragmented information on line. So professional development is necessary for the TV official accounts to survive in the rat race. Only in this way, they can transform from the single-screen communication of traditional media to cross-screen communication and achieve the real media convergence. Taking China Blue, the official account of Zhejiang TV, for example, after clicking the Running Man, the users can watch the hot variety shows such as Voice of China 4 and Running Man 3, which is helpful 
to promote the influence of programs on traditional media, and attract more users for WeChat official accounts to.

Traditional media should learn to integrate resources and use the Internet platform to integrate and communicate other social media platforms such as Weibo, WeChat to create an organic unity of online and offline, and the brand media so as to enhance the audience rating of the programs, the subscriptions of official accounts and a fixed audience group to further expand the television station's economic benefit and social influence.

When operating the official account, the TV stations should combine their own communication characteristics and continue to explore in the media integration, and constantly form a three-dimensional transmission pattern with more powerful influence in virtue of brand advantages of media. At the same time, the TV stations should further provide users with better service, and pay more attention to interaction with users, so that the TV media can be bigger and stronger in the fierce competition in the Internet.

\section{References}

CAI, W., \& WENG, Z. J. (2013). WeChat public platform: Another opportunity for the change of news communication. Journalism Review, 7, 40-44.

HUANG, C. X., \& PENG, Y. J. (2016). The development status, problems and suggestions of China's TV WeChat official account. China Radio \& TV Academic Journal, 3, 47-51.

HUANG, C. X., \& WANG, D. (2015). Status, types and development trend of WeChat's Official Accounts. News and Writing, 7 , 5-9.

JING, J. (2015). The editing and rule exploration of headlines of WeChat official accounts-Taking the Official Accounts of Renmin Website as an example.

LI, R. J., \& LIU, Y. (2016). Research on the operation and countermeasures of WeChat Official Accounts. Radio \& TV Journal, 9 , 11-13.

LIU, J. J., YANG, S. J., \& SHEN, Y. (2014). Analysis on the official accounts of ttraditional media Wechat in 2014. News and Writing, 12, 16-19.

LUO, X. H. (2015). The editing strategy of WeChat Official Accounts news content. Journalism Research Herald, 7, $143-144$.

YU, X. O. (2015). Study on “People's Daily” WeChat Official Accounts. Liaoning University.

ZHAO, J., \& LI, B. (2013). A preliminary study on the development of WeChat public platform. Practical Journalism, 8, 8-10. 